\title{
Microbial carrying capacity and carbon biomass of plastic marine debris
}

\author{
Shiye Zhao ${ }^{1}$ Erik R. Zettler ${ }^{2}$ Linda A. Amaral-Zettler ${ }^{2,3,4} \cdot$ Tracy J. Mincer $\mathbb{1}^{1,5}$
}

Received: 22 March 2020 / Revised: 1 July 2020 / Accepted: 21 August 2020 / Published online: 2 September 2020

(c) The Author(s), under exclusive licence to International Society for Microbial Ecology 2020

\begin{abstract}
Trillions of plastic debris fragments are floating at sea, presenting a substantial surface area for microbial colonization. Numerous cultivation-independent surveys have characterized plastic-associated microbial biofilms, however, quantitative studies addressing microbial carbon biomass are lacking. Our confocal laser scanning microscopy data show that early biofilm development on polyethylene, polypropylene, polystyrene, and glass substrates displayed variable cell size, abundance, and carbon biomass, whereas these parameters stabilized in mature biofilms. Unexpectedly, plastic substrates presented lower volume proportions of photosynthetic cells after 8 weeks, compared to glass. Early biofilms displayed the highest proportions of diatoms, which could influence the vertical transport of plastic debris. In total, conservative estimates suggest $2.1 \times 10^{21}$ to $3.4 \times 10^{21}$ cells, corresponding to about $1 \%$ of the microbial cells in the ocean surface microlayer $(1.5 \times$ $10^{3}$ to $1.1 \times 10^{4}$ tons of carbon biomass), inhabit plastic debris globally. As an unnatural addition to sea surface waters, the large quantity of cells and biomass carried by plastic debris has the potential to impact biodiversity, autochthonous ecological functions, and biogeochemical cycles within the ocean.
\end{abstract}

\section{Introduction}

Trillions of plastic particles are floating at sea [1] and provide a substantial surface area for microbial colonization [2]. Plastic marine debris (PMD) microbial biomass has been

Supplementary information The online version of this article (https:// doi.org/10.1038/s41396-020-00756-2) contains supplementary material, which is available to authorized users.

Tracy J. Mincer

tmincer@fau.edu

1 Harbor Branch Oceanographic Institute, Florida Atlantic University, Fort Pierce, FL 34946, USA

2 Department of Marine Microbiology and Biogeochemistry, NIOZ Royal Netherlands Institute for Sea Research and Utrecht University, Den Burg, Texel, The Netherlands

3 Department of Freshwater and Marine Ecology, Institute for Biodiversity and Ecosystem Dynamics, University of Amsterdam, Amsterdam, The Netherlands

4 Josephine Bay Paul Center for Comparative Molecular Biology and Evolution, Marine Biological Laboratory, Woods Hole, MA, USA

5 Department of Biology, Wilkes Honors College, Florida Atlantic University, Jupiter, FL 33458, USA hypothesized to range from 860 to 16,000 metric tons [3, 4] compared to the total mass of PMD ( 268,940 tons) in the global ocean [5]. With the potential to be transported across marine ecosystem boundaries, microbial biomass on PMD represents an emerging perturbation to the fragile oligotrophic ocean habitats with unknown biogeochemical and ecological consequences. Although poorly understood, the quantification of cell numbers and microbial biomass on PMD (referenced herein as microbial carrying capacity) is crucial for understanding the implications of PMD on oceanic ecosystems.

Employing culture-independent approaches and scanning electron microscopy (SEM), Zettler et al. [6] described the microbial communities on microplastic litter from the North Atlantic, which were distinct from ambient seawater communities. This plastic-associated biofilm, coined the "plastisphere", consists of a complex community comprised of bacterial, archaeal, and eukaryotic microorganisms, and microscopic animals. Since then, plastisphere research has largely employed molecular ecology methods focused on characterization of these microbial biofilm communities, their correlation to environmental and geographical factors, and variation between plastic substrates [7, 8]. In these field studies, the unknown origin and age of field-collected plastic debris have impeded the determination of substrate-specific biofilm composition. A growing number of experimental 
studies have directly compared different synthetic polymerassociated biofilm assemblages and nonplastic substrates exposed to the identical environments (Table S1). But few studies, summarized in the Table S1, have incorporated a time-course element to their incubation schemes.

SEM and DNA sequence-based microbial survey techniques, methods widely used in plastisphere research, each have advantages and limitations when quantifying diverse microbial biofilm assemblages. The well-established microscopic technique of SEM fails to detect cells embedded within a biofilm in three dimensions [9], but provides information on spatial structure at the surface. Sequencing provides detailed information on taxonomy of the whole community, but multiple copies of SSU rRNA genes per cell, ranging $1-17$ for bacteria and in up to $10^{4}$ for protists, provide an innate bias for quantitative estimates [10]. Quantitative real-time PCR (Q-PCR) allows estimates of target gene sequence concentrations in environmental samples, and taxon-specific Q-PCR primer sets can provide cell numbers for a single taxon [11], but a posteriori knowledge of target groups present is crucial. In addition, sets of degenerate oligonucleotide primers designed for different targets have various reaction kinetics leading to inaccuracies during Q-PCR, and other errors such as DNA extraction efficiency, PCR template properties, and data analysis can lead to several orders of magnitude bias [11].

Confocal laser scanning microscopy (CLSM) has been used extensively to nondestructively study biofilm structure [12]. Recording the signal of different fluorochromes together with natural pigment fluorescence (such as the phytopigment chlorophyll $a($ Chl-a)), CLSM has been employed to differentiate between phototrophs, heterotrophs, bacteria, archaea, and eukaryotes [12]. Furthermore, analysis of CLSM images with computer software can directly obtain data ranging from cell counts, size and the characterization of microbial morphotypes, to complete three-dimensional constructs [13]. More recently, CLASIFISH or Combinatorial Labeling and Spectral Imaging Fluorescence In Situ Hybridization visualized plastisphere membership of multiple taxa on polyethylene (PE) via custom group specific rRNA-based phylogenetic probes and CLSM [14]. This study compared relative bacterial counts via CLSM to those derived from amplicon sequencing in a time-series study taken from the same incubation experiment as described in this report.

Here we employed CLSM in combination with digital image analysis to directly count cells in order to determine biomass contribution of the whole microbial community (bacteria, archaea, and eukaryotes) and ascertain the carrying capacity of the plastisphere. We chose two fluorophores: Hoechst 33342, capable of penetrating diverse cell membranes and intercalating double stranded DNA; and FM 1-43, a lipophilic styryl dye used to stain membranes of diverse cell types. This combination allowed us to determine cell abundances and morphologies on a range of chemically distinct substrates (PE; polypropylene, PP; polystyrene, PS; Glass). The selection of these test substrates was dependent on the varying index of their previously reported hydrophobicity $[15,16]$, which allowed testing whether this physicochemical surface property can influence the microbial assemblages on the substratum surfaces. In addition, we used Chl- $a$ autofluorescence as a proxy for quantifying cells capable of photosynthesis. All substrate samples were simultaneously incubated at the Marine Biological Laboratory dock (Woods Hole, Massachusetts, USA) from July to October 2013. Cell volume measurements allowed an estimation of carbon biomass to be calculated based on previously published "carbon/ volume $(\mathrm{C} / \mathrm{vol})$ " relationships and measurements of carbon per cell for various microbial taxa [17, 18]. Our approach allowed us to address the following questions: (1) how do cell abundances, size, cellular carbon mass, and photosynthetic cells differ on polymeric and glass substrates over time? (2) What is the average microbial biomass carrying capacity of different plastic polymers and, by extension, PMD in the global ocean?

\section{Materials and methods}

\section{Biofilm incubations}

In situ incubations consisted of placing postconsumer plastic from 1-gallon milk jugs (PE), disposable cold-drink cups (PP), disposable hot-drink cups (PS), and glass cubes off a dock in Woods Hole, Massachusetts, in Vineyard Sound (GPS coordinates: 41.525, -70.673). The items were cleaned and then sterilized using $70 \%$ ethanol prior to placing them in the seawater, $\sim 1 \mathrm{~m}$ below the surface in July 2013 in 1-cm mesh nylon cages to prevent plastic samples from escaping. Subsamples $(\sim 5 \times 5 \mathrm{~mm})$ were taken at periodic time points $(1,2,3,8,12$ weeks of immersion) thereafter and rinsed in $0.2-\mu \mathrm{m}$-filtered seawater to remove unattached organisms. Attached biofilms were preserved by placing the plastic in $4 \%(\mathrm{w} / \mathrm{v})$ paraformaldehyde in $0.2 \mathrm{M}$ phosphate buffered saline (PBS) for $3 \mathrm{~h}$ at $4{ }^{\circ} \mathrm{C}$ immediately after removing the samples from seawater, then transferring them to PBS/ethanol at $-20^{\circ} \mathrm{C}$ for long-term storage.

\section{Staining procedure}

All cellular DNA was labeled with the blue fluorescent Hoechst 33342 (Life Technologies, Eugene, OR), a sensitive and broad-spectrum intercalating stain effective for bacteria, archaea, fungi, and microbial eukaryotes. The lipid membrane dye FM 1-43 FX (Life Technologies, Eugene, 
OR) was employed for the visualization of individual microbial cells within a biofilm matrix. Both stains were used according to the recommendations of the manufacturer (Table S2). A detailed description of the procedure can be found in the Supplementary section.

\section{CLSM}

A Carl Zeiss LSM 780 system configured on an inverted Observer Z1 microscope was used to acquire the images of biofilms at the Central Microscopy Facility (Marine Biological Laboratory, Woods Hole). Images were obtained with a $40 \times 1.3$ NA Plan-Apochromat oil-immersion objective. For each sample, 20 fields of view were randomly imaged, except for PS at week 8, where 14 fields of view were collected. A total of 214 images were acquired in this study. Daily calibrations for magnification and sensitivity were performed using $4 \mu \mathrm{m}$ microsphere beads from the TetraSpeck ${ }^{\mathrm{TM}}$ Fluorescent Microspheres Size Kit (Invitrogen, Carlsbad, CA). CLSM Images of TetraSpeck ${ }^{\mathrm{TM}}$ Microsphere beads acquired at three lasers were used as a reference to adjust the acquisition settings such as pinhole, gain, and voltage levels. Additional details can be found in the Supplementary section.

\section{Quantification of total cell numbers and photosynthetic cells}

To quantify cell abundances within the biofilms, all images of z-stacks were processed using IMARIS 9.3.0 (Bitplane, Zurich, Switzerland). Cells stained with both Hoechst 33342 and FM 1-43 were assessed using the "coloc" function. The constructed colocalization images were rendered as 3D images with the "iso-surface" function. If the cells in the iso-surface rendered images, which were initially separate, were merged in the reconstruction, we manually split them with the "cut surface" tool. This served to capture most cells, but some merged cells were overlooked, leading to undercounting of cells. In all, 60-100 connected cells per counting view were processed with our "cut surface" editing, which could provide an averaged prediction missing signal (5.4\%) over all the counting views. Finally, we quantified the cell number using the spot detection function. We estimated the cell abundance (cells/ $\mathrm{mm}^{2}$ ) harbored in the plastisphere by summing the total cell numbers (direct counts in each Z-stack image) and dividing by the area covered by the images.

Quantifying the volume-based proportion of Chl-a fluorescence as a function of the total biofilm volume enabled us to monitor the dynamics of autofluorescent cells (presumed phototrophs) within the biofilms. For each 3DCLSM image, the volumes of Chl- $a$ fluorescence and all cells were quantified by constructing a 3D iso-surface based on signals from the Chl- $a$ and FM 1-43 channels, individually. Subsequently, the proportional Chl-a volume was calculated by normalizing the volume of signals in the $\mathrm{Chl}$ $a$ channel to those in the FM 1-43 channel. The manual selection of the threshold was applied based upon visual inspection throughout the imaging quantification.

\section{Calculation of cellular carbon on PMD}

The carbon biomass of cells was estimated based on published C:vol relationships of marine microbes [18, 19]. Generally, three subblocks of each image were subsampled along the diagonal direction (Fig. S1). Cell dimensions (length and width, $\mu \mathrm{m}$ ) in the subsampled blocks were measured manually on the images. Five images from each sample were randomly selected and measured. A total of 165 subsampled blocks were analyzed, and 12,613 cells were measured.

Our calculation of cellular carbon was based on previously determined bacterial, archaeal, and eukaryotic cellcarbon values and procedures [19-22] which are detailed in the Supplementary section. In addition, all detailed methods for determining PMD surface area, calculation of biomass $[22,23]$, and statistical evaluations can be found in the Supplementary section.

\section{Results}

\section{Biofilm structures characterized by CLSM}

Microbial cells were heterogeneously distributed on all four types of substratum over the period of incubation (Fig. 1). Microscopy images showed that pennate diatoms dominated biofilm communities at week 1. At later stages (8week incubation), biofilms became more crowded and diverse, and other photosynthetic and non-photosynthetic microbes supplanted the diatoms (Fig. 1).

\section{Cell size and abundance dynamics}

All measured cell sizes were in the range of $0.84-54.6 \mu \mathrm{m}$ in length and 0.46-23.7 $\mu \mathrm{m}$ in width (Fig. S2). Cell abundances between substrates and abundances on all substrates were observed to increase over the incubation experiment (Fig. 2 and Table S3). These abundances were combined with ocean surface plastic inventory literature values to estimate global contributions (Table S4). At week 1, the cell abundances on PE were much higher than the three other substrates (Kruskal-Wallis test, $\chi^{2}=25, p<0.05$; paired Mann-Whitney-Wilcoxon test, $p<0.05$, Fig. 2), but at week 8 no significant differences in cell abundances on the three plastic substrates were detected. However, a 
Fig. 1 Three-dimensional visualization of biofilm on four substrates after 1 week (left column) and 8 weeks (right column) of immersion. Color allocation: blue-DNA intercalated with Hoechst 33342, red-FM1-43 styryl membrane stain, greenphotopigment autofluorescence, yellow is resulting overlay of red and green signal. Arrows in the top panels indicate autofluoresence of a typical microalga. Scale bar is $20 \mu \mathrm{m}$.

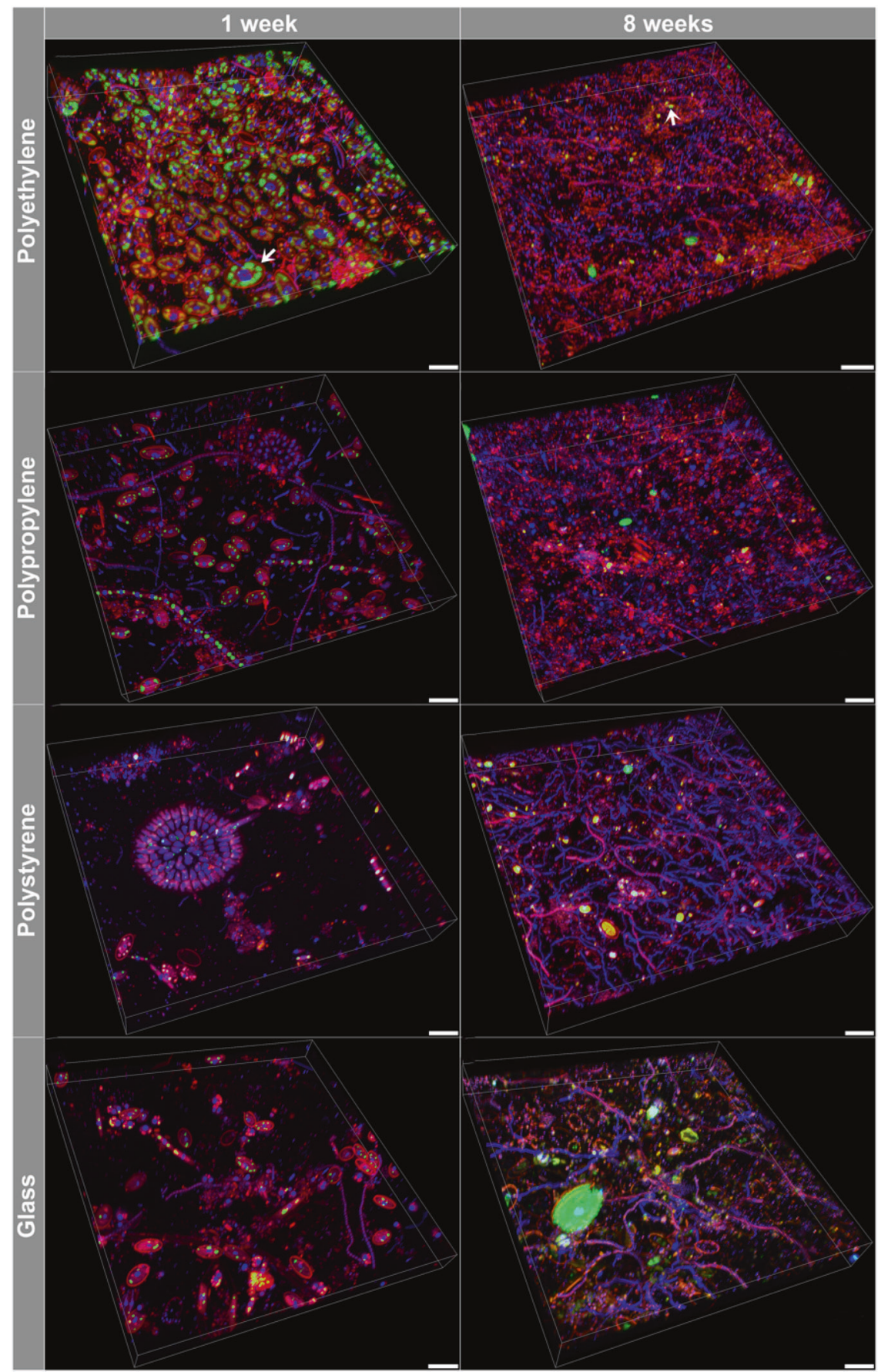

significantly lower cell density $\left(0.8 \times 10^{5} \pm 0.3 \times 10^{5}\right.$ cells/ $\mathrm{mm}^{2}$ ) was observed on the glass compared to all plastics (paired Mann-Whitney-Wilcoxon test, $p<0.05$, Fig. 2). The cell abundances on all substrates at week 8 displayed a significant increase (up to threefold) compared to those at week 1 (Mann-Whitney-Wilcoxon test, $p<0.05$, Fig. 2, Tables S3, S5, and S6). For PE, we analyzed five additional time points, and cell abundances generally increased over the incubation period (Fig. S3). Kernel density estimation for the cell length showed the cell size distribution shifts toward smaller cells on all four substrates with longer exposure periods (Figs. 3 and S4). The average estimated cell volumes dropped quickly over time on all substrates (Fig. S5), and after the 1st week of incubation for PE (Fig. S6).

\section{Proportional Chl-a volume within all biofilm cells}

There were differences in Chl- $a$ volume proportion between most substrates after 1 week of incubation (Kruskal-Wallis 
test, paired Mann-Whitney-Wilcoxon test, $p<0.05$, Table S7), except no difference was observed between PP and PS. At week 8, proportional Chl-a volumes differed statistically between PE and PP (paired Mann-Whitney-Wilcoxon test, $p<0.05$ ), but no differences were found across other substrates (paired

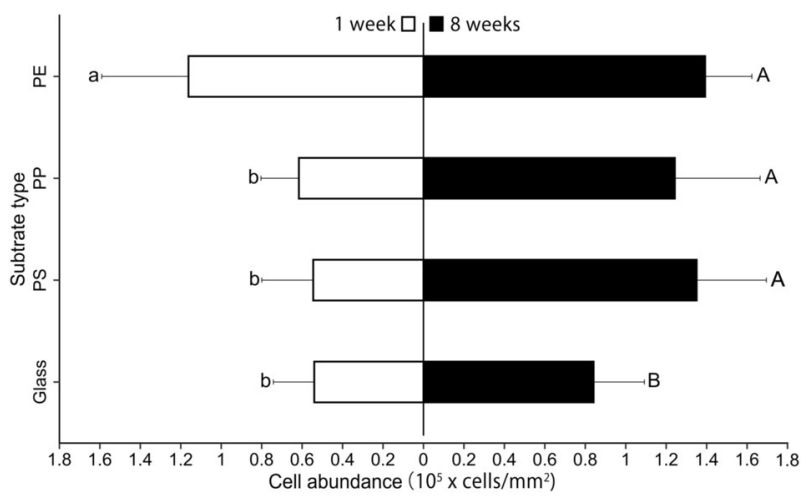

Fig. 2 Cell abundance $\left(10^{5} \times\right.$ cells $\left./ \mathrm{mm}^{2}\right)$ on four substrates after 1 week and 8 weeks of immersion. Values indicate mean \pm SD. Not sharing a common letter at the same time point means there was a statistically significant difference between cell abundances (Kruskal-Wallis test, paired Mann-Whitney-Wilcoxon test, $p<0.05$ ).
Mann-Whitney-Wilcoxon test, $p>0.05$ ). PE at week 8 had a higher phototroph volume than the other substrates (Kruskal-Wallis test, paired Mann-Whitney-Wilcoxon test, $p<0.05$, Table S7).

At week 1, significantly higher proportions of Chl-a volumes within all biofilm cells were detected on three plastic substrates than at week 8 (Kruskal-Wallis test: PE, $\chi^{2}=42.1, p \ll 0.001$; Mann-Whitney-Wilcoxon test: PP, $W=284, p \ll 0.001 ; \mathrm{PS}, W=94, p \ll 0.001)$. Overall, biofilm autofluorescence volumes at week 1 were higher than those at week 8 (Fig. 4a). In contrast, the proportions of the autofluorescence volume on glass displayed no significant difference between weeks 1 and 8 .

\section{Carbon biomass on substrates}

Carbon biomasses were significantly different between PE, PP, PS, and glass substrates at week 1 (Kruskal-Wallis test, paired Mann-Whitney-Wilcoxon test, $p<0.05$, Table S7). PE had the largest carbon mass value, followed by glass, PP, and PS (Fig. 4b). Differences in carbon biomasses were also found between three of the substrates at week 8
Fig. 3 Curves show kernel density estimations for the cell length distributions on four substrates after 1 and 8 weeks of immersion. Black dots represent the actual size of each cell individually measured in the CLSM images.

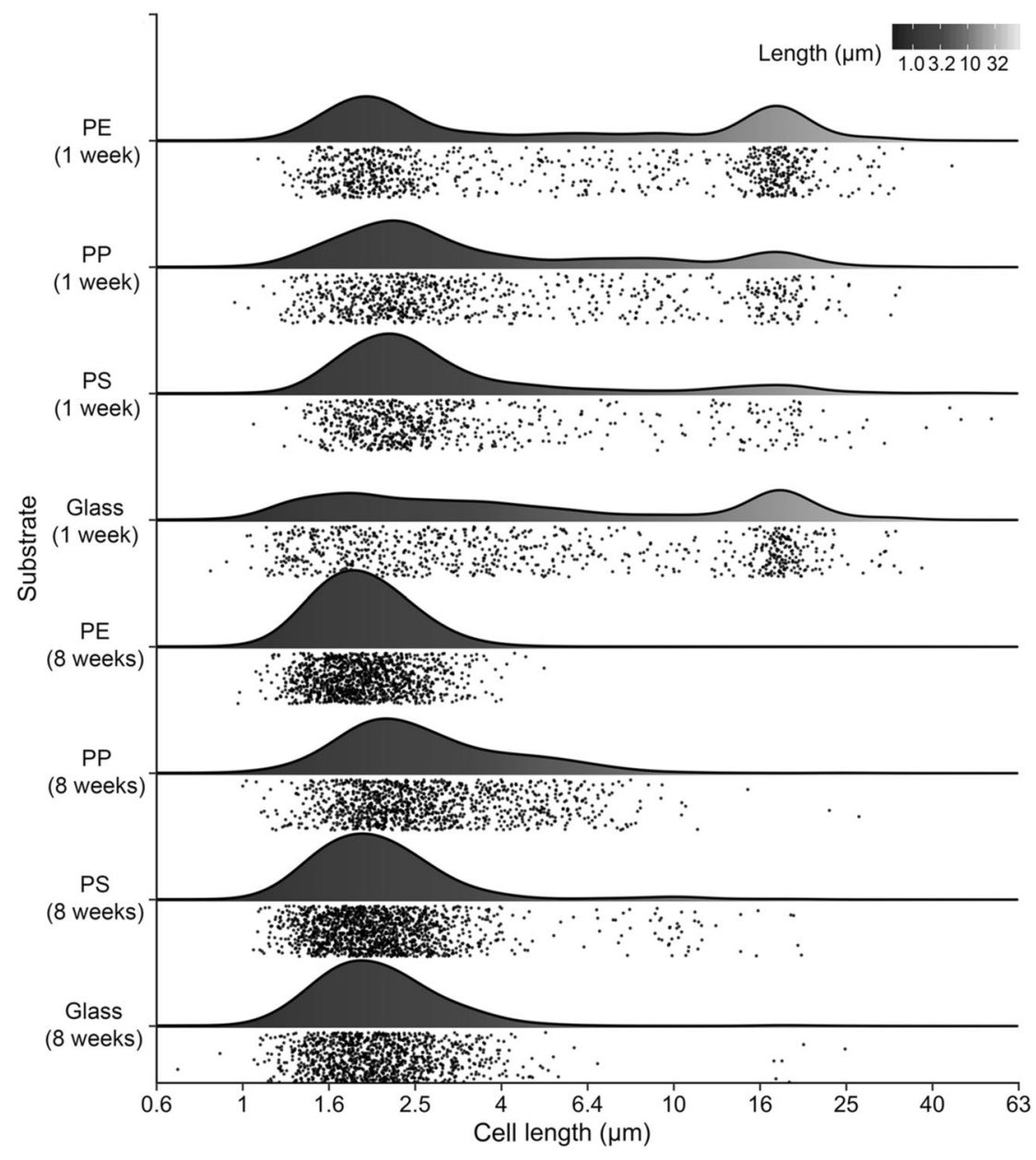



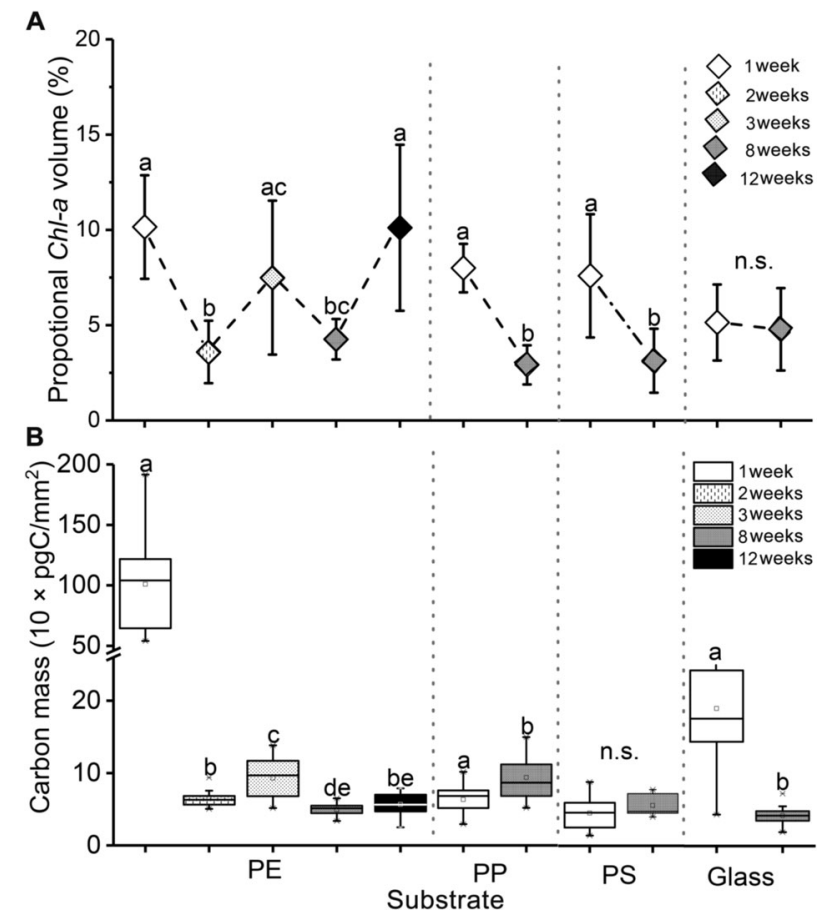

Fig. 4 Temporal development of biofilms over the incubation period on four substrates (polyethylene (PE), polypropylene (PP), polystyrene (PS), glass (Glass)). a Biovolume proportion (\%) of chlorophyll a fluorescence within the total biofilm volume. Data are means \pm standard error of the mean. $\mathbf{b}$ The estimated carbon mass $\left(10^{4} \times \mathrm{pgC} / \mathrm{mm}^{2}\right)$. Not sharing a common letter between different time points of the same substrate indicates statistically significant differences (ns $=$ no significance) based on Kruskal-Wallis and Mann-Whitney-Wilcoxon tests $(p<0.05)$.

(Kruskal-Wallis test, paired Mann-Whitney-Wilcoxon test, $p<0.05$, Table S7).

Total carbon biomass on PE and Glass decreased temporally from week 1 to 8, while total carbon biomass on PP increased (Kruskal-Wallis test, paired Mann-Whitney-Wilcoxon test, $p<0.05$, Fig. 4b and Table S5). PE in particular at week 1 supported 10-20-fold more carbon biomass than the other substrates but dropped quickly at week 2 and remained at levels similar to the other substrates until week 12 (Fig. 4b).

\section{Discussion}

Biofilm formation in the marine environment is a complex process, involving many variables, however, emerging patterns from previous studies correlate with our data set. Diatoms have been repeatedly reported as important colonizers of marine plastic since the first reference to plastic in the ocean $[3,14,24-26]$ and as shown in Fig. 1 (oval green cell morphologies), pennate diatoms in the present study dominated the biofilm communities on all four substrate types after 1 week of immersion. Pennate diatoms commonly dominate the biofilm community, irrespective of the nature of the substrata [27], while at later stages, the abundance of diatoms generally declines with the increasing colonization of other microorganisms $[14,26]$.

Dense diatom monolayers on plastics can result in a buoyancy decrease and net downward transport of plastic particles from the surface layer [28-30]. A significantly higher (10-20-fold) carbon biomass in the early biofilm on $\mathrm{PE}$, dominated by pennate diatoms, was observed in our study (Figs. 1 and 4b), suggesting that normally buoyant plastic pieces with sufficiently high surface area/volume ratios could be prone to sinking at the initial stages of biofilm formation, particularly for PE. Our 3D images and observed morphological features (e.g., shape and size) of microbes on four substrates (Figs. 1 and 3) showed that diatoms became considerably less abundant in the late successional stages for all substrates tested, except PS. Thus, it is plausible that diatoms dominating plastic surfaces are a common pattern in the early stages of biofilm formation in the marine environment.

No significant differences of proportional phototrophic volumes were found on glass between weeks 1 and 8 . This finding is in disagreement with Mueller et al. [31], who grew phototrophic biofilms on glass slides over 44 days in flowing unfiltered North Sea water and found a linear increase in phototrophic biovolumes by quantifying CLSM images. A possible explanation for this difference is that their experimental set-up (biofilms were grown in $70 \mathrm{~L}$ containers in natural seawater) was under relatively steady state conditions in contrast to the natural conditions in our study where biofilm formation is disturbed by various environmental factors such as protist grazing [32]. Our study also differs from this study in that they represented the absolute volumes of phototrophs by quantifying the CLSM images, while we compared proportional volumes of phototrophs. In contrast to glass, we observed lower proportions of phototrophic volumes on three plastic treatments at week 8 compared to those at week 1 (Fig. 4a). This implies that differences in the chemistry between plastics and glass may contribute to this differentiation in the responses of photosynthetic organisms. Recently, laboratory experiments showed plastic leachates of high-density PE and polyvinyl chloride, including inorganic and organic chemicals, significantly reduce the in vitro growth and photosynthesis in Prochlorococcus spp., the most abundant photosynthetic bacterial taxon in the ocean [33]. Similarly, Capolupo et al. [34] documented that leachates from PP and PS apparently inhibited the growth of the marine microalga, Skeletonema costatum. Although the leachates of postconsumer plastics used in our study were not monitored, it is plausible that these commercial plastic products containing various additives and adsorbed chemicals could act as a chemical cue to influence the primary productivity within the plastisphere. In addition, biofilms are thought to 
act as a trophic link between dissolved nutrients in the water column and the higher trophic levels of the aquatic ecosystem [35]. The decreased relative volumes of phototrophs on plastic substrates at week 8 (Fig. 4a) would potentially affect the growth rate of the secondary consumers in the community.

Cell abundances on substrates increased during the exposure time (Figs. 2 and S3), with a maximum found on $\mathrm{PE}$ at week 8 . These changes indicate progressive biofilm stages over time, from the initial colonizers altering the physicochemical substratum surface conditions toward more secondary colonizers at later stages that have also been observed in previous studies [27, 32]. The average cell counts on four substrates (ranging from $0.5 \times 10^{4}$ to $1.8 \times$ $10^{5}$ cells $/ \mathrm{mm}^{2}$ ) were comparable to a previous study that enumerated microplastics from the Western Mediterranean Sea $\left(4.4 \times 10^{4}\right.$ cells $\left./ \mathrm{mm}^{2}\right)$ [36]. In our study, we observed a successional pattern of attached microbes clearly transitioning from larger to smaller cell volumes both qualitatively (Fig. 1), and quantitatively from cell dimensional analysis (Figs. 3 and S4). Our results show the relative abundance of eukaryotic community (cell length: $>2 \mu \mathrm{m}$ ) on four substrates declined over the exposure time, contrasting modestly with a recent study on plastisphere incubation research in the Caribbean Sea that identified an increasing trend of diatoms monitored by SEM over a 6-week incubation [24]. This discrepancy may be due to differences in geographic conditions and communities or microscopic methods. However, Dudek et al. [24] also incubated their plastic samples in nylon bags with a 1-mm mesh size, which could have deterred grazing of the surfaces by some invertebrates, such as harpacticoid copepods known to selectively feed upon diatoms in biofilms [37]. In contrast, plastic samples in our study were incubated in cages with a $1-\mathrm{cm}$ mesh. Grazing of diatoms has been commonly observed by Schlundt et al. [14], who used SEM to analyzed biofilm on plastics from the same incubation experiment as described in this report.

Changes in the $\mathrm{C} / \mathrm{vol}$ relationship and cell abundances led to variations in the area-specific carbon biomass on different substrates between weeks 1 and 8 . The five sequential time points for PE (Fig. 4) appear to show an oscillation in carbon biomass and proportions of phototrophic volumes over the incubation period (high, low, high, low, high). This is in keeping with the observations by Yokota et al. [38], who cultured the cyanobacterium Dolichospermum flosaquae with various microplastics and found statistically significant differences in abundances as a function of incubation time, suggesting indicating a dynamic interaction between physicochemical properties of plastic, microbial communities, its life cycles, and environmental factors [28, 38]. This dynamic, possibly cyclic pattern is suggested by our PE data, however, longer incubations with more frequent sampling would be necessary to verify this cell-carbon oscillation.

\section{Substrate-driven biofilm structures}

Incubation experiments of plastic substrates in the marine environment have demonstrated that the physiochemical characteristic of the substratum surface (such as hydrophobicity, surface texture, and chemical nature) can affect colonizing communities [16, 32, 39-42], and surface hydrophobicity has been considered as a factor affecting microbial cell adhesion because microbes attach more rapidly to hydrophobic surfaces than hydrophilic surfaces $[15,43,44]$. Previous research reported that diatom genera (such as Achnanthes, Amphora, Cocconeis, Navicula, and Synedra) adhered more strongly to hydrophobic surfaces, inhibiting motility and release, than hydrophilic surfaces, where diatom gametes swarming and release was enhanced [45]. With respect to the substrate types used in our study, $\mathrm{PE}$ is the most hydrophobic (water contact angle, $\theta=$ $\left.101.7^{\circ}\right)$, followed by PP $\left(\theta=99^{\circ}\right)$, PS $\left(\theta=87^{\circ}\right)$, and glass $\left(\theta=51^{\circ}\right)$ in descending order with lower water contact values indicating more hydrophilic surfaces [16]. Hence, we predicted that more hydrophobic surfaces could harbor more microbial cells initially and our data demonstrated this by the descending order of cell abundances per area on PE, PP, PS, and glass at week 1 (Fig. 2), however, this trend has not been as clearly observed by other researchers. For example, Ogonowski et al. [16] did not report a correlation between bacterial abundance and substrate hydrophobicity after incubating PE, PP, PS, and glass substrates in the Baltic Sea for 2 weeks. These disparate results could be due to differing methods employed, where we made direct counts of cells, while Ogonowski et al. [16] estimated bacterial abundances by Q-PCR analysis of $16 \mathrm{~S}$ rRNA genes using a primer set with broad phylogenetic specificity, which was better suited for their overall investigation of understanding how microbial assemblages varied with substrate variability. Another factor complicating direct comparison of the results of Ogonowski et al. [16] and our study is the fact that $16 \mathrm{~S}$ rRNA operon copy numbers can range from 1 to 17 per bacterial genome and are strain specific. A higher $16 \mathrm{~S}$ rRNA operon copy number per genome of a specific taxon can create bias up to an order of magnitude or greater in comparison to individuals with a lower copy number [10]. In contrast, we determined cell abundances via direct counts of microbes, although this approach might miss some microorganisms in the $1-2 \mu \mathrm{m}$ range due to the complex structure of the biofilm hampering Hoechst 33342 cell membrane penetration. Thus, it is likely that cell abundances are underestimated in our study, but we maintain that these errors are consistent between samples 
and the plastisphere contributes slightly more $\mathrm{C}$ than we report.

Some substrates inhibit the formation of biofilms $[16,38]$. Of the three plastic substrates, we observed the lowest cell abundance on PS surfaces at week 1, which was around threefold lower than that at week 8 (Fig. 2 and Table S3). This could be attributed to the potential interaction between the styrene monomers and microorganisms. Styrene monomers have proven to be toxic to microbes in anaerobic treatment systems [46], and could potentially act as a negative chemical cue for the settlement of microorganisms.

Despite the differences in cell abundances, we did not find a clear correlation between biovolume (carbon biomass) per area and substrate hydrophobicity at week 1 or 8 (Fig. 4b). At week 8, cell abundance on glass was lower, in contrast to plastic substrates. Compared to inorganic glass substrates, plastic polymers have been suggested as an active carbon source for the attached microbial community $[6,16]$, which could encourage more effective cell proliferation. But no distinctions of area-specific cell abundance on the three plastic substrates at week 8 could be explained by the similar surface attributes, which implies that the influence of surface properties on the adhesion of microbes is only apparent at the initial stages and decreases with maturation of the biofilm. This finding is in agreement with Kettner et al. [41], who found the abundances of fungi on PE and PS showed no differentiation after incubation in seawater for 15 days, in contrast to distinctions between plastics and wood. Recently, Pinto et al. [47] reported that the plastic-specific bacteria among PE, PP, and polyvinyl chloride surfaces were less variable and abundant at later stages than those at early stages. These observations also suggest that biofilm communities at later stages are more structured by changes in colonization and biofilm characteristics, rather than by the substrate properties [48].

\section{Microbial carrying capacity on a global scale}

Based on the reported plastic counts and size classes floating in the world's ocean [5] and the general abundances of different plastic debris in ocean surface water [23], we estimate that PMD could provide a total surface area of $2.5 \times 10^{10} \mathrm{~m}^{2}$ (Table S4). The plastic surface area estimation assigns a particle diameter of $200 \mathrm{~mm}$ to any plastic afloat at sea, which results in a conservative surface prediction. This surface area value of PMD indicates a potentially large and durable surface for microbial colonization. Trace nutrients are concentrated on solid surfaces in the water column, becoming more bioavailable and stimulating bacterial respiration [49]. This "Zobell" effect can have a significant influence. For instance, the subtropical gyres are accumulation zones for buoyant PMD [5] and nutrientlimited ocean regions [50, 51]. Thus, PMD in the oligotrophic subtropical gyres could provide a nutritional benefit for sessile microbes, altering the open ocean community and microbial loop by stimulating attached communities and gross production, while simultaneously stripping nutrients from the water column, inhibiting the growth of free-living cells.

Integrating over the calculated PMD distribution in the world's ocean, we estimated the total number of cells on plastic debris to be $2.1 \times 10^{21}$ to $3.4 \times 10^{21}$. This value is roughly equal to $\sim 1 \%$ of microbial cells $\left(2 \times 10^{23}\right.$ cells $)$ in the global ocean neuston surface microlayer [52]. Because much of the PMD is concentrated in the oligotrophic central gyres, this may lead to unknown consequences for the surrounding microbial water-column community diversity and function, and biogeochemical cycles in the open ocean. This number is three orders of magnitude lower than the numbers of microbial cells in the global rivers $\left(1.2 \times 10^{24}\right.$ cells) and both polar regions $\left(4.0 \times 10^{24}\right.$ cells) [53]. Multiplying plastic surface area by the area-specific carbon biomass at the early and late stages of biofilm on plastic substrates, the total amount of carbon biomass in these plastic-associated cells is predicted to be $1.5 \times 10^{3}$ to $1.1 \times$ $10^{4}$ metric tons, which is roughly similar with the previous estimate of living biomass $\left(8.6 \times 10^{2}\right.$ to $1.6 \times 10^{4}$ metric tons) on PMD [3]. Our higher bound carbon estimate $(1.1 \times$ $10^{4}$ metric tons) approaches the estimated cellular carbon mass in the global rivers $\left(2.4 \times 10^{4}\right.$ metric tons), as well as both polar regions $\left(8 \times 10^{4}\right.$ metric tons) [53]. It should be noted that our values of cell numbers and carbon contents include both eukaryotes and bacteria/archaea, in contrast to bacterial and archaeal cells alone, as were quantified by Whitman et al. [53].

This introduction of carbon biomass on PMD can provide a potentially extra "carbon source" for the biota in the ocean, especially the oligotrophic subtropical gyres, the oceanic accumulation zone of PMD. Although grazing the surface of PMD has been reported from all levels of the marine trophic web, the transfer of energy between plasticassociated microbial assemblages and pelagic communities has not been well characterized. The first step to elucidate the ecological role of PMD is to understand the formation, structure, dynamics, and especially carbon content and nutritional value of bacterial/archaeal and eukaryotic cells in the plastisphere. We emphasize that our carbon biomass estimates on PMD above should be considered conservative. Contrasted with the similar size ranges of bacteria and archaea (picoplankton-sized cells), eukaryotic cell volumes (nano- and microplankton-sized cells) vary by several orders of magnitude in our measurements (Figs. S5 and S6), which would have resulted in highly variable amounts of carbon mass per cell. Therefore, median and 
mean carbon biomass data were used to calculate the carbon content of eukaryotes and bacteria/archaea, respectively. To estimate the cell number and carbon mass on "other" polymer types (plastic debris besides PE, PP, and PS) at the global level, the minimum values of carbon per cell, cell abundances, and eukaryotes to bacteria/archaea ratios from the measured PE, PP, PS were selected (Table S6). Moreover, the $\mathrm{Clvol}$ relationship for diatoms was employed to estimate the carbon content of all eukaryotic cells in our study. Among all published $\mathrm{C} / \mathrm{vol}$ equations for eukaryotes, the conversion factors for diatoms resulted in the minimum $\mathrm{C}$ value for each cell [19]. In addition, we know that some cells in our 3D biofilms were obstructed from view, and we assumed a maximum plastic particle diameter of $200 \mathrm{~mm}$. Size fractions rigorously determined by Eriksen et al. [5] allow us to make a more constrained calculation of plastic substrate areas. Moreover, the employment of the estimated plastic counts (5.25 trillion pieces [5]) in the global ocean is three to ten times lower than the most recent estimation (15-51 trillion particles) by Van Sebille et al. [1], which also results in the underestimation of the PMD microbial carrying capacity. Finally, we considered only the microbial community in calculating our carbon mass estimates, ignoring the contribution of macrofouling communities of metazoans that often thickly coat PMD, particularly the larger pieces. Future studies should incorporate the whole community, as well as spatial and temporal patterns of cell numbers and carbon biomass on PMD from the global ocean to determine their impacts on the overall oceanic ecosystem.

It is important to emphasize two limitations of the methods used to estimate carbon biomass in our study. First, microscopic image analysis could impact the accuracy of cell size and count measurements, including the lack of robust discrimination between bacterial, archaeal, and eukaryotic microorganisms, through illumination and halo effects with the fluorescent cells causing overestimation of biomass, the resolving power of microscopy, and the automatic algorithm of the image segmentation [54, 55]. A second principal limitation is the use of empirically derived "carbon/volume" relationships to estimate the cellular carbon contents, often used for microbial biomass estimates $[13,56,57]$. A significant amount of "carbon/volume" conversion factors/models have been measured and vary significantly $[17,18]$. These differences can be derived from the heterogeneity in species composition of the environmental samples studied and the different physiological state of pure cultures [58]. Therefore, biomass estimates based on defined "carbon/volume" relationships could introduce uncertainties in the biomass estimates. Using other published conversion factors/formulas [17, 58], the estimated global carbon mass calculated values on PMD varied, however, they are still close (changing our lower and upper estimates by about $32 \%$ and $<5 \%$, respectively) to our current calculations (Table S8). We also emphasize that the global estimate of biomass serves as a benchmark for further studies of determining the "microbial carrying capacity" of PMD.

Introduced $<50$ years ago, plastic substrates are a novel microbial habitat in the world's oceans [3,6]. Although several studies have surveyed microbial diversity and quantified specific members of these biofilm habitats, ours is the first to holistically quantify total cell inventories under in situ conditions. Our study design allowed carrying capacity to be quantified and comparisons of microbial biomass to be made among different polymer substrates over time using a relatively non-biased, direct cell staining, and counting method. As a "foreign" perturbation in marine systems, the comparatively large quantity of cells and carbon biomass carried by floating plastic debris could exert unknown consequences on the biodiversity, ecological functions, and biogeochemical cycles within the ocean. Indeed, each plastic particle in the marine environment can be considered a microbial reservoir harboring microbes' orders of magnitude higher in density than the surrounding open ocean community. Future efforts should focus on how this biomass fluctuates with season and latitude and its potential to perturb the flux of nutrients in the upper layers of the ocean.

\section{Data availability}

All data needed to evaluate the conclusions in the paper are present in the paper and/or the Supplementary Materials. Additional data related to this paper may be requested from the authors.

Acknowledgements Thanks to Gregory Boyd, Jessica Fields, and Kiera Saleem for their help with sampling. We also thank Louis Kerr of the Central Microscope Facility at the Marine Biological Laboratory for technical support. The work was also supported by NSF collaborative grants to LAA-Z (OCE-1155571), ERZ (OCE-1155379), and TJM (OCE-1155671), NOAA grant NA17NOS9990024 to LAA-Z an American Chemistry Council award to LAA-Z, ERZ, and TJM, and funds from FAU World Class Faculty and Scholar Program to TJM.

Author contributions All authors were involved in conceiving the study. TJM, SZ, LAA-Z, and ERZ designed the experiments; TJM, LAA-Z, and ERZ conducted the incubation experiment. SZ analyzed the samples. SZ carried out the data analysis and wrote the paper with significant assistance and comments from all the other authors.

\section{Compliance with ethical standards}

Conflict of interest The authors declare that they have no conflict of interest.

Publisher's note Springer Nature remains neutral with regard to jurisdictional claims in published maps and institutional affiliations. 


\section{References}

1. Van Sebille E, Wilcox C, Lebreton L, Maximenko N, Hardesty BD, Van Franeker JA, et al. A global inventory of small floating plastic debris. Environ Res Lett. 2015;10:124006.

2. Reisser J, Shaw J, Hallegraeff G, Proietti M, Barnes DK, Thums M, et al. Millimeter-sized marine plastics: a new pelagic habitat for microorganisms and invertebrates. PLoS ONE. 2014;9:e100289.

3. Mincer TJ, Zettler ER, Amaral-Zettler LA. Biofilms on plastic debris and their influence on marine nutrient cycling, productivity, and hazardous chemical mobility. In: Rei Yamashita KT, Bee Geok Yeo, Hideshige Takada, Jan A. van Franeker, Megan Dalton, Eric Dale, editors. Hazardous chemicals associated with plastics in the marine environment. Springer: Cham; 2016. pp. 221-33.

4. Morét-Ferguson S, Law KL, Proskurowski G, Murphy EK, Peacock EE, Reddy CM. The size, mass, and composition of plastic debris in the western North Atlantic Ocean. Mar Pollut Bull. 2010;60:1873-8.

5. Eriksen M, Lebreton LC, Carson HS, Thiel M, Moore CJ, Borerro JC, et al. Plastic pollution in the world's oceans: more than 5 trillion plastic pieces weighing over 250,000 tons afloat at sea. PLoS ONE. 2014;9:e111913.

6. Zettler ER, Mincer TJ, Amaral-Zettler LA. Life in the "plastisphere": microbial communities on plastic marine debris. Environ Sci Technol. 2013;47:7137-46.

7. Amaral-Zettler LA, Zettler ER, Slikas B, Boyd GD, Melvin DW, Morrall CE, et al. The biogeography of the plastisphere: implications for policy. Front Ecol Environ. 2015;13:541-6.

8. De Tender CA, Devriese LI, Haegeman A, Maes S, Ruttink T, Dawyndt P. Bacterial community profiling of plastic litter in the Belgian part of the North Sea. Environ Sci Technol. 2015;49:9629-38.

9. De Tender CA, Schlundt C, Devriese LI, Mincer TJ, Zettler ER, Amaral-Zettler LA. A review of microscopy and comparative molecular-based methods to characterize "plastisphere" communities. Anal Methods. 2017;9:2132-43.

10. Gong W, Marchetti A. Estimation of $18 \mathrm{~S}$ gene copy number in marine eukaryotic plankton using a next-generation sequencing approach. Front Mar Sci. 2019;6:219.

11. Bonk F, Popp D, Harms H, Centler F. PCR-based quantification of taxa-specific abundances in microbial communities: quantifying and avoiding common pitfalls. J Microbiol Methods. 2018;153:139-47.

12. Neu TR, Lawrence JR. Innovative techniques, sensors, and approaches for imaging biofilms at different scales. Trends Microbiol. 2015;23:233-42.

13. Bochdansky AB, Clouse MA, Herndl GJ. Eukaryotic microbes, principally fungi and labyrinthulomycetes, dominate biomass on bathypelagic marine snow. ISME J. 2017;11:362-73.

14. Schlundt C, Welch JLM, Knochel AM, Zettler ER, Amaral-Zettler LA. Spatial structure in the "plastisphere": molecular resources for imaging microscopic communities on plastic marine debris. Mol Ecol Resour. 2020;20:620-634.

15. Bruinsma G, Van der Mei H, Busscher H. Bacterial adhesion to surface hydrophilic and hydrophobic contact lenses. Biomaterials. 2001;22:3217-24.

16. Ogonowski M, Motiei A, Ininbergs K, Hell E, Gerdes Z, Udekwu $\mathrm{KI}$, et al. Evidence for selective bacterial community structuring on microplastics. Environ Microbiol. 2018;20:2796-808.

17. Khachikyan A, Milucka J, Littmann S, Ahmerkamp S, Meador T, Könneke M, et al. Direct cell mass measurements expand the role of small microorganisms in nature. Appl Environ Microbiol. 2019;85:e0493-19.

18. Romanova N, Sazhin A. Relationships between the cell volume and the carbon content of bacteria. Oceanology. 2010;50:522-30.
19. Menden-Deuer S, Lessard EJ. Carbon to volume relationships for dinoflagellates, diatoms, and other protist plankton. Limnol Oceanogr. 2000;45:569-79.

20. Massana R, Logares R. Eukaryotic versus prokaryotic marine picoplankton ecology. Environ Microbiol. 2013;15:1254-61.

21. Loferer-Krößbacher M, Klima J, Psenner R. Determination of bacterial cell dry mass by transmission electron microscopy and densitometric image analysis. Appl Environ Microbiol. 1998;64:688-94.

22. Lee S, Fuhrman JA. Relationships between biovolume and biomass of naturally derived marine bacterioplankton. Appl Environ Microbiol. 1987;53:1298-303.

23. Erni-Cassola G, Zadjelovic V, Gibson MI, Christie-Oleza JA. Distribution of plastic polymer types in the marine environment; a meta-analysis. J Hazard Mater. 2019;369:691-8.

24. Dudek KL, Cruz BN, Polidoro B, Neuer S. Microbial colonization of microplastics in the Caribbean Sea. Limnol Oceanogr Lett. 2020;5:5-17.

25. Carpenter EJ, Smith K. Plastics on the Sargasso Sea surface. Science. 1972;175:1240-1.

26. Amaral-Zettler LA, Zettler ER, Mincer TJ. Ecology of the plastisphere. Nat Rev Microbiol. 2020;18:139-51.

27. Patil JS, Anil AC. Biofilm diatom community structure: influence of temporal and substratum variability. Biofouling. 2005;21:189-206.

28. Rummel CD, Jahnke A, Gorokhova E, Kühnel D, Schmitt-Jansen M. Impacts of biofilm formation on the fate and potential effects of microplastic in the aquatic environment. Environ Sci Technol Lett. 2017;4:258-67.

29. Michels J, Stippkugel A, Lenz M, Wirtz K, Engel A. Rapid aggregation of biofilm-covered microplastics with marine biogenic particles. Proc R Soc B. 2018;285:20181203.

30. Lobelle D, Cunliffe M. Early microbial biofilm formation on marine plastic debris. Mar Pollut Bull. 2011;62:197-200.

31. Mueller LN, de Brouwer JF, Almeida JS, Stal LJ, Xavier JB. Analysis of a marine phototrophic biofilm by confocal laser scanning microscopy using the new image quantification software PHLIP. BMC Ecol. 2006;6:1.

32. De Tender CA, Devriese LI, Haegeman A, Maes S, Vangeyte JR, Cattrijsse A, et al. Temporal dynamics of bacterial and fungal colonization on plastic debris in the North Sea. Environ Sci Technol. 2017;51:7350-60.

33. Tetu SG, Sarker I, Schrameyer V, Pickford R, Elbourne LD, Moore LR, et al. Plastic leachates impair growth and oxygen production in Prochlorococcus, the ocean's most abundant photosynthetic bacteria. Commun Biol. 2019;2:1-9.

34. Capolupo M, Sørensen L, Jayasena KDR, Booth AM, Fabbri E. Chemical composition and ecotoxicity of plastic and car tire rubber leachates to aquatic organisms. Water Res. 2020;169:115270.

35. Vosshage AT, Neu TR, Gabel F. Plastic alters biofilm quality as food resource of the freshwater Gastropod Radix balthica. Environ Sci Technol. 2018;52:11387-93.

36. Dussud C, Meistertzheim A, Conan P, Pujo-Pay M, George M, Fabre $\mathrm{P}$, et al. Evidence of niche partitioning among bacteria living on plastics, organic particles and surrounding seawaters. Environ Pollut. 2018;236:807-16.

37. Armitage AR, Gonzalez VL, Fong P. Decoupling of nutrient and grazer impacts on a benthic estuarine diatom assemblage. Estuar Coast Shelf Sci. 2009;84:375-82.

38. Yokota K, Waterfield H, Hastings C, Davidson E, Kwietniewski E, Wells B. Finding the missing piece of the aquatic plastic pollution puzzle: interaction between primary producers and microplastics. Limnol Oceanogr Lett. 2017;2:91-104.

39. Oberbeckmann S, Kreikemeyer B, Labrenz M. Environmental factors support the formation of specific bacterial assemblages on microplastics. Front Microbiol. 2018;8:2709. 
40. Kirstein IV, Wichels A, Krohne G, Gerdts G. Mature biofilm communities on synthetic polymers in seawater-specific or general? Mar Environ Res. 2018;142:147-54.

41. Kettner MT, Rojas-Jimenez K, Oberbeckmann S, Labrenz M, Grossart HP. Microplastics alter composition of fungal communities in aquatic ecosystems. Environ Microbiol. 2017;19:4447-59.

42. Kettner MT, Oberbeckmann S, Labrenz M, Grossart HP. The eukaryotic life on microplastics in brackish ecosystems. Front Microbiol. 2019;10:538.

43. Bayoudh S, Othmane A, Bettaieb F, Bakhrouf A, Ouada HB, Ponsonnet L. Quantification of the adhesion free energy between bacteria and hydrophobic and hydrophilic substrata. Mater Sci Eng C. 2006;26:300-5.

44. Bendinger B, Rijnaarts HH, Altendorf K, Zehnder AJ. Physicochemical cell surface and adhesive properties of coryneform bacteria related to the presence and chain length of mycolic acids. Appl Environ Microbiol. 1993;59:3973-7.

45. Thompson SE, Coates JC. Surface sensing and stress-signalling in Ulva and fouling diatoms-potential targets for antifouling: a review. Biofouling. 2017;33:410-32.

46. Araya P, Chamy R, Mota M, Alves M. Biodegradability and toxicity of styrene in the anaerobic digestion process. Biotechnol Lett. 2000;22:1477-81.

47. Pinto M, Langer TM, Hüffer T, Hofmann T, Herndl GJ. The composition of bacterial communities associated with plastic biofilms differs between different polymers and stages of biofilm succession. PLoS ONE. 2019;14:e0217165.

48. Datta MS, Sliwerska E, Gore J, Polz MF, Cordero OX. Microbial interactions lead to rapid micro-scale successions on model marine particles. Nat Commun. 2016;7:11965.
49. Zobell CE. The effect of solid surfaces upon bacterial activity. J Bacteriol. 1943;46:39-56.

50. Karl DM, Björkman KM, Dore JE, Fujieki L, Hebel DV, Houlihan $\mathrm{T}$, et al. Ecological nitrogen-to-phosphorus stoichiometry at station ALOHA. Deep Sea Res Part II: Topical Stud Oceanogr. 2001;48:1529-66.

51. Steinberg DK, Carlson CA, Bates NR, Johnson RJ, Michaels AF, Knap AH. Overview of the US JGOFS Bermuda Atlantic Timeseries Study (BATS): a decade-scale look at ocean biology and biogeochemistry. Deep Sea Res II. 2001;48:1405-47.

52. Flemming H-C, Wuertz S. Bacteria and Archaea on Earth and their abundance in biofilms. Nat Rev Microbiol. 2019;17:247.

53. Whitman WB, Coleman DC, Wiebe WJ. Prokaryotes: the unseen majority. Proc Natl Acad Sci. 1998;95:6578-83.

54. Bjørnsen PK. Automatic determination of bacterioplankton biomass by image analysis. Appl Environ Microbiol. 1986;51:1199-204.

55. Bloem J, Veninga M, Shepherd J. Fully automatic determination of soil bacterium numbers, cell volumes, and frequencies of dividing cells by confocal laser scanning microscopy and image analysis. Appl Environ Microbiol. 1995;61:926-36.

56. Kallmeyer J, Pockalny R, Adhikari RR, Smith DC, D'Hondt S. Global distribution of microbial abundance and biomass in subseafloor sediment. Proc Natl Acad Sci. 2012;109:16213-6.

57. Pernice MC, Forn I, Gomes A, Lara E, Alonso-Sáez L, Arrieta $\mathrm{JM}$, et al. Global abundance of planktonic heterotrophic protists in the deep ocean. ISME J. 2015;9:782-92.

58. Bölter M, Bloem J, Meiners K, Möller R. Enumeration and biovolume determination of microbial cells-a methodological review and recommendations for applications in ecological research. Biol Fertil Soils. 2002;36:249-59. 